\title{
Edukasi Perlindungan Hak Milik Melalui Pendaftaran dan Pemeliharaan Data Tanah di RW 14 Kelurahan Tanjung Periuk
}

\author{
Sufiarina1, Esther Tarigan ${ }^{2}$, Rina Tauran ${ }^{3}$, Eni Jaya ${ }^{4}$, Elianta Ginting ${ }^{5}$ \\ 1,2,3,4,5, Program Studi Ilmu Hukum Fakultas Hukum, Universitas Tama Jagakarsa \\ *e-mail : sufiarina01@gmail.com
}

\begin{abstract}
The land ownership right is only intended for Indonesian citizens; however, protection of property right is carried out through land registration. Nevertheless, during a difficult time of pandemic, land assets and their property rights need to be considered, especially in urban areas where value of land keeps increasing. Among community members in RW 14 Kelurahan Tanjung Periuk, even though they are only few kilometers away from National Palace, evidently there are still residents' land that has not been registered. There are still residents who have not adjusted the data on land ownership regarding with the change of rights land. Currently, government, through articles in 87 PP No.18 in 2021 requires the acceleration of land a registration process. It is necessary to provide education to the community about the importance of protecting rights of land in the form of counseling with the hope that local community will realize the necessity of land rights registration process and appreciate the benefits of adjusting data of land registration.
\end{abstract}

Keywords: Registration of land, handling of land registration data

\begin{abstract}
Abstrak
Penguasaan hak atas tanah berupa hak milik hanya diperuntukkan bagi warga negara Indonesia secara individual. Perlindungan hak milik terlaksana melalui pendaftaran tanah. Meskipun di masa pandemi covid yang menyulitkan, asset atas tanah berupa hak milik tetap harus diperhatikan. Apalagi di wilayah perkotaan, nilai tanah cenderung meningkat dan terus meningkat. Warga masyarakat di RW 14 Kelurahan Tanjung Periuk Jakut, meskipun hanya berjarak beberapa kilometer saja dari istana negara ternyata masih ada tanah hak warga yang belum terdaftar. Masih ada warga yang belum melakukan penyesuaian data hak atas tanah, sehubungan terjadinya perubahan data hak. Saat ini pun Pemerintah melalui Pasal 87 PP No. 18 Tahun 2021, menghendaki terjadinya percepatan pendaftaran tanah. Perlu diberikan edukasi pada masyarakat setempat akan pentingnya perlindungan hak atas tanah. Edukasi berupa penyuluhan dengan harapan masyarakat setempat menyadari pentingnya pendaftaran hak dan memahami manfaat penyesuaian data pendaftaran tanah.
\end{abstract}

Kata kunci; pendaftaran tanah, pemeliharaan data pendaftaran tanah

\section{PENDAHULUAN}

Persentasi kepemilikan sertifikat sebagai produk pendaftaran tanah untuk pertama kali di Indonesia tergolong masih relatif rendah (Harris Yonatan Parmahan Sibuea:2011). Pelaksanaan pendaftaran tanah di Indonesia belumlah optimal, dari 126 juta bidang tanah hanyalah 46 juta saja yang telah didaftar. Berarti masih terdapat 80 juta bidang tanah lagi yang belum didaftar (Dian Aries Mujiburohman:2018). Sedangkan tumbuhnya bidang-bidang tanah melebihi 1 juta bidang setiap tahunnya (Dian Aries Mujiburohman:2018).

Disadari begitu pentingnya pendaftaran hak atas tanah bagi pemegang haknya. Melalui pendaftaran diperoleh kepastian dan perlindungan hak atas tanah. Dilaksanakannya kegiatan pendaftaran hak atas tanah dapat mencegah sekaligus menjadi dasar penyelesaian sengketa tanah. Konflik mengenai tanah selaku permukaan bumi dikarenakan pengakuan pihak lainnya atas sebidang tanah dapat dihindari bila sebidang tanah telah didaftarkan pada Kantor 
Pertanahan (Kantah) (Rahmi:2009;Gawil Despriyatmoko:2016). Dengan pendaftaran tanah dimungkinkan pula terjadi peningkatan secara ekonomi atas bidang tanah. Selain bagi pemegang hak, data pendaftaran tanah juga penting bagi pemerintah sebagai sumber informasi guna mengambil kebijakan.

Secara alami manusia merupakan makhluk monodualis, artinya manusia selaku makhluk individual sekaligus juga selaku makhluk sosial (Rudi Indrajara:2020). Sebagai individu, negara telah memberikan hak penguasaan atas tanah berupa hak milik hanya bagi perseorangan warga negara Indonesia, sebagaimana Pasal 21 Undang-Undang No. 5 Tahun 1960. Dengan demikian ditentukan hanyalah warga negara sebagai rakyat Indonesia selaku individual semata yang dimungkinkan memegang hak atas tanah berupa kepemilikan di bumi pertiwi ini. Merupakan upaya melindungi oleh pembentuk undang-undang bagi rakyat selaku warga negara Indonesia dalam penguasaan tanah berupa milik. Hak milik atas tanah sebagai hak terkuat dan terpenuh yang bersifat turun temurun sebagaimana Pasal 20 UU No. 5 Tahun 1960. Penguasaan hak milik tentunya mempunyai banyak keuntungan dibandingkan dengan penguasaan tanah dengan hak lain.

Pemerintah menghendaki terjadinya percepatan pendaftaran tanah. Pasal 87 PP No. 18 Tahun 2021 menentukan perlunya percepatan pendaftaran tanah. Pelaksanaan pendaftaran tanah secara sistematik (secara massal mengikuti program kementerian) wajib diikuti pemilik bidang tanah. Bila tidak didaftar secara sistematik maka pemilik bidang tanah wajib mendaftarkan hak atas tanahnya secara sporadik (individual). Telah terjadi pergeseran aturan terkait pendaftaran tanah. Semula dibebankan pada pemerintah, saat ini justru pemilik tanah diwajibkan untuk mendaftarkan bidang tanahnya. Perkembangan hukum sangat dipengaruhi oleh kondisi ideologi, politik, sosial, dan budaya (Rina Yulianti: 2021).

Kepastian hukum penguasaan tanah dengan pemilikan dapat dibuktikan dengan sertifikat yang diterbitkan badan pertanahan. Dokumen sertifikat sebagai bukti tertulis untuk membuktikan secara kuat hubungan hukum pemegang hak dengan tanah yang telah didaftarkan. Bilamana kemudian didapat perubahan data atas penguasaan hak milik bagi tanah yang sudah didaftar, maka perlu dilakukan penyesuaiannya dengan pengkinian data atau disebut dengan pemeliharaan data pendaftaran tanah pada kantor pertanahan.

Berarti ada dua hal berkaitan dengan pendaftaran tanah yaitu:

1. Pendaftaran tanah untuk pertama kalinya;

2. Pemeliharaan data pendaftaran tanah.

Kegiatan pendaftaran bidang tanah untuk kali pertamanya dikategorikan penting guna mendapatkan pengakuan hukum atas hubungan pemegang hak milik dengan tanahnya. Dikarenakan bidang tanah yang telah didaftar mendapatkan sertipikat serta mempunyai kepastian hukum. Pembuktian hak atas tanah berupa sertifikat memiliki nilai lebih dibandingkan dengan bukti tertulis lainnya (Darwin Ginting:2011). Sertifikat hak atas tanah mempunyai daya pembuktian yang kuat.

Pentingnya pemeliharaan data pendaftaran tanah guna mendapatkan kesesuaian antara dokumen bukti hak dengan keadaan saat ini, bila kemudian terjadi perubahan. Artinya bermaksud untuk mendapatkan kekinian dari data yuridis maupun data fisik keadaan bidang tanah yang telah didaftarkan (Akur Nurasa, Dian Aries Mujiburohman:2020).

Masyarakat di wilayah Rukun Warga (RW) 014 Kelurahan Tanjung Periuk yang berlokasi di ibukota negara dan hanya berjarak sekitar 13,4 KM saja dari Istana Negara. Wilayah RW 14 Kelurahan Tanjung Periuk, terlihat sangat padat penduduk dengan pemukiman yang saling berdempetan. Ternyata masih terdapat adanya penguasaan tanah oleh warga yang belum 
dilakukan pendaftaran. Dan juga belum dilakukan pengkinian atas perubahan data tanah yang telah didaftar. Padahal telah ada hal-hal yang mengubah data tanahnya. Perlunya penyesuaian data pendaftaran tanah agar dokumen bukti haknya selalu cocok dengan keadaan yang sebenarnya.

Pihak pemerintah khususnya Kantor Pertanahan Jakarta Utara telah berupaya meningkatkan tanah terdaftar melalui kegiatan Pendaftaran Tanah Sistematik Lengkap (PTSL). Hiskiya Simarmata selaku Kepala Kantah Jakarta Utara, menyampaikan cakupan di wilayahnya, Jakarta Utara dan Kab. Kepulauan Seribu, sudah ada 8 kelurahan yang telah diselesaikan pendaftaran tanahnya hingga mencapai 100 persen. Kelurahan dimaksud adalah kelurahan Panggang, Tidung, Pulau Untung Jawa, Pulau Kelapa, Pulau Harapan, Pulau Pari, Rawa Badak Utara dan kelurahan Koja (Pontas.Id, 2020).

Untuk wilayah Kelurahan Tanjung Periuk khususnya RW 14, selaras dengan penyampaian Kepala Kantor Pertanahan Jakarta Utara, masih ada tanah milik yang dikuasai masyarakat belum didaftar. Artinya belum seluruh bidang tanah di RW 14 yang berhasil terdaftar. Untuk itu bagi masyarakat Tanjung Periuk, khususnya di wilayah RW 14 dipandang perlu diberikan penyuluhan sebagai edukasi pentingnya mendaftarkan hak atas tanahnya dan juga memelihara data tanah yang telah didaftar.

\section{METODE}

Metode yang digunakan dalam pemberian edukasi kepada Warga RW 14, Kelurahan Tanjung Periuk. Merupakan wujud pelaksanaan mengabdikan ilmu pada masyarakat dengan metode Partisipatori Rural Apracial (PRA). Sebagai metode pendekatan dalam proses pemberdayaan dan peningkatan partisipasi masyarakat. Penekanannya ditujukan pada keterlibatan masyarakat secara langsung berdasarkan pada kedekatan identitas, minat, perasaan memiliki, dan, tempat tinggal lokasi/kelompok (Mustanir\&Lubis:2017). Khususnya digunakan metode berdasarkan lokasi tempat tinggal yaitu warga yang berdomisili di RW 14. Kelurahan Tanjung Periuk Jakarta Utara.

Setelah melakukan observasi, Tim Pelaksana Pengabdian, memilih edukasi bidang pendaftaran dan pemeliharaan data pendaftaran tanah. Warga RW 14 Kelurahan Tanjung Periuk diberikan edukasi tentang pentingnya mendaftarkan hak milik atas tanah dan manfaat memelihara data tanah yang telah didaftarkan. Penyuluhan ditujukan kepada 12 Ketua Rukun Tetangga (RT), dan juga diikuti para ibu Dasa Wisma dan Pengurus PKK RW 14 Kelurahan Tanjung Periuk, serta beberapa Mahasiswa.

a. Diberikan edukasi melalui penyuluhan dengan penggunaan diksi yang mudah dipahami warga. Dijelaskan mengenai persyaratan dokumen yang diperlukan bagi kegiatan mendaftarkan haknya atas tanah. Dijelaskan pula persyaratan dokumen yang diperlukan dalam penyesuaian data pemeliharaan data tanah.

b. Disampaikan bahwa kegiatan pendaftaran tanah untuk pertama kali dimungkinkan mengikuti program pemerintah melalui Pendaftaran Tanah Sistemik Lengkap (PTSL). Sedangkan penyesuaian dan pemeliharaan data pendaftaran tanah sepenuhnya merupakan inisiatif dan menjadi kewajiban pemegang hak.

c. Warga RW 14 Kelurahan Tanjung Periuk, diedukasi mengenai pentingnya perlindungan hak atas tanah dengan pendaftaran serta manfaat pemeliharaan data pendaftaran tanah. Disampaikan bahwa pendaftaran tanah dan penyesuaian datanya dapat meningkatkan nilai ekonomis tanah, sebagai upaya mencegah sengketa dan penyelesaian sengketa pertanahan. 
d. Dilanjutkan dengan agenda tanya jawab guna menyerap permasalahan warga. Atas permasalahan yang dikemukakan, dengan cara memberikan arahan dan penjelasan sebagai saran bagi penyelesaian problem yang dikemukakan.

\section{HASIL DAN PEMBAHASAN}

Pelaksanaan pengabdian dengan edukasi melalui penyuluhan mengenai pentingnya pendaftaran tanah dan pemeliharaan data pendaftaran tanah. Kegiatan dilaksanakan di hari Sabtu, tanggal 31 Juli 2021. Dikarenakan masih dalam suasana Pemberlakuan Pembatasan Kegiatan Masyarakat (PPKM Tahap 2), maka edukasi dilakukan melalui zoom meeting dengan dihadiri 71 partisipan.

Pemberian edukasi melalui penyuluhan dengan cara membukakan wawasan masyarakat RW 14 Kel. Tanjung Periuk Jakarta Utara. Diharapkan warga yang belum mendaftarkan hak milik atas tanahnya untuk segera melengkapi dokumen yang dibutuhkan. Bagi warga yang belum melakukan pemeliharaan data pendaftaran tanah, agar segera melaksanakan penyesuaian data pendaftaran tanah, guna melindungi hak milik atas tanahnya.

Dari hasil diskusi dan tanya jawab terlihat warga RW 14 Kelurahan Tanjung Periuk telah ada peningkatan kepedulian untuk melindungi hak miliknya atas tanah. Terbukti dengan pertanyaan yang dilontarkan berkaitan langsung dengan perlindungan hak dan pemeliharaan data pendaftaran tanah mereka. Warga RW. 14 Kelurahan Tanjung Periuk, telah paham pentingnya perlindungan hak atas tanah melalui pendaftaran hak dan memelihara data tanah yang telah didaftarkan.

Berkaitan perbuatan mengalihkan atau memindahkan hak milik, yang terjadi bukanlah pemindahan tanahnya. Sesungguhnya yang diperalihkan adalah hak atas tanahnya (J. Andi Hartanto:2014). Pendaftaran peralihan sebagai bentuk pemeliharaan data tanah. Kegiatan pemeliharaan data tanah ini membutuhkan keberadaan bukti secara tertulis berupa sertifikat bagi tanah yang telah terdaftar. Sedangkan bagi tanah yang belum terdaftar diperlukan keberadaan bukti pendukung. Bukti tertulis dalam jual beli tanah dimaksudkan dalam bentuk akta jual beli. Keberadaan dokumen guna pemenuhan persyaratan legal menurut regulasi yang berlaku. Dokumen yang dibutuhkan untuk memelihara data tanah yang telah didaftarkan, karena adanya perbuatan pengalihan berupa jual beli dan karena terjadinya pewarisan dapat dilihat dari tabel berikut adalah:

Tabel 1. Kebutuhan Dokumen

\begin{tabular}{llc}
\hline No & \multicolumn{1}{c}{ Kebutuhan Dokumen } & $\begin{array}{c}\text { Kepentingan } \\
\text { Pendaftaran Oleh }\end{array}$ \\
\hline 1 & $\begin{array}{l}\text { Pewarisan } \\
\text { Peralihan hak karena warisan, penerima hak } \\
\text { perlu menyerahkan: }\end{array}$ & Ahli Waris \\
a. Sertipikat tanah; & \\
b. Keterangan meninggalnya pewaris; & \\
c. Keterangan sebagai Ahli Waris; \\
d. Akta pembagian warisan (bila ahli waris & \\
$\quad$ lebih dari satu) & Pembeli \\
2 Jual Beli & \\
Beralihnya hak karena jual beli; & \\
a. Akta Jual Beli oleh PPAT & \\
b. Sertipikat tanah &
\end{tabular}


Hasil kegiatan pengabdian masyarakat berupa edukasi perlindungan hak melalui pendaftaran dan pemeliharaan data pendaftaran tanah pada warga RW 14 Kelurahan Tanjung Periuk. Masih terdapat tanah yang dikuasai warga dan belum dilakukan pendaftaran. Dan ada tanah milik warga yang belum dilakukan penyesuian data pendaftaran tanah karena belum dibuatkan akta jual belinya di hadapan PPAT, sedangkan pihak penjual tidak dapat lagi ditemui.

Perubahan penguasaan hak atas tanah dikarenakan jual beli, memerlukan keberadaan Akta oleh Pejabat Pembuat Akta Tanah (PPAT). Sedangkan perubahan data hak atas tanah karena pewarisan diperlukan surat keterangan meninggalnya pewaris dan surat keterangan selaku ahli waris (Adrian Sutedi:2008).

Syarat utama pemindahan hak atas tanah berdasar Pasal 37 PP No. 24 tahun 1997, haruslah dibuktikan dengan akta PPAT. Bilamana dalam transaksi jual beli hak milik, karena sesuatu hal hanya dilakukan secara di bawah tangan. Dalam arti tidak atau belum ada dibuatkan Akta Jual Beli di hadapan PPAT. Sedangkan untuk penyesuaian atau pemeliharaan data pendaftaran tanah syarat utamanya adalah akta jual beli yang dibuatkan oleh PPAT. Perlu diprioritaskan pencarian dan menemukan kembali pihak penjual. Kemudian pihak pembeli dan penjual bersama-sama menghadap PPAT untuk mendapatkan Akta Jual Beli.

Tetapi apabila pihak penjual sudah tidak dapat ditemukan lagi. Bila pihak pembeli telah membayarkan harga tanah secara lunas, sertipikat hak atas tanahpun sudah berada di tangan pembeli begitu juga tanahnya sudah dikuasai pembeli. Keadaan itu saja tak akan dapat dilakukan pemeliharaan data pendaftaran tanah dengan mengalihkan kepemilikan dari nama penjual kepada nama pembeli. Agar dapat dilakukan penyesuaian atau pemeliharaan data pendaftaran tanah, maka alternatif yang dapat dijalankan sebagai upaya akhir berupa pengajuan surat gugatan ke Pengadilan Negeri. Dimana pembeli yang beriktikat baik mengajukan gugatannya. Gugatan diajukan untuk memperoleh putusan yang memberikan legalitas bagi pembeli untuk bertindak sebagai diri sendiri selaku pembeli, dan juga untuk bertindak atas nama tergugat selaku penjual dalam menghadap kepada PPAT. Dengan demikian maka pemeliharaan data pendaftaran tanah yang telah beralih kepada pembeli dapat diselenggarakan oleh Kantor Pertanahan.

\section{KESIMPULAN}

Dari kegiatan penyelenggaraan pengabdian masyarakat dengan tema edukasi perlindungan hak milik atas tanah melalui pendaftaran dan pemeliharaan data pendaftaran tanah pada masyarakat warga RW 14 Kelurahan Tanjung Periuk Jakarta Utara ini dapat dinyatakan berjalan baik dan sukses. Pernyataan ini dibuktikan dengan antusiasnya warga mempertanyakan hal-hal berikut yang telah diberikan penjelasan dalam pertemuan virtual:

a. Diperlukan adanya akta PPAT, bagi pemeliharaan data tanah yang telah didaftarkan, bila terjadi peralihan hak karena jual beli. Dan diperlukan surat keterangan meninggalnya pewaris serta surat keterangan sebagai ahli waris dan atau surat keterangan pembagian warisan di antara para ahli waris.

b. Warga yang belum melakukan pemeliharaan data pendaftaran tanah karena belum mempunyai Akta Jual Beli, dan pihak penjual tak lagi bisa ditemui, maka solusi terakhirnya dengan mengajukan gugatan untuk mendapatkan putusan pengadilan yang memberikan wewenang kepada pembeli untuk bertindak selaku pembeli dan juga selaku penjual, apabila pembayaran tanah telah dibayarkan secara lunas, dan sertipikat hak sudah ada di tangan pembeli. 


\section{UCAPAN TERIMA KASIH}

Dengan telah terlaksana kegiatan pengabdian kepada masyarakat oleh Tim Pelaksana Edukasi dari Fakultas Hukum Universitas Tama Jagakarsa perlu disampaikan ucapan terima kasih atas dukungan yang telah diberikan. Ucapan terima kasih disampaikan kepada Rektor, Dekan dan LPPM yang telah memberikan dukungan atas pelaksanaan PKM ini.

\section{DAFTAR PUSTAKA}

Adrian Sutedi, (2008) Peralihan Hak Atas Tanah dan Pendaftarannya, Sinar Grafika, Jakarta, Akur Nurasa dan Dian Aries Mujiburohman,(2020) Pemeliharaan Data Pendaftaran Tanah, STPN Press Bekerja sama dengan Program Studi DIV STPN, 2020, http://repository.stpn.ac.id/521/1/Buku\%20Pemeliharaan\%20Data\%20Pendafataran\%20 Tanah_opt.pdf diunduh tanggal 25 Juli 2021

Andy Hartanto (2014), Hukum Pertanahan, Laksbang Yustisia, Surabaya, 2014, hlm 65

Darwin Ginting 2011. Reformasi hukum tanah dalam rangka perlindungan hak atas tanah perorangan dan penanam modal dalam bidang agrobisnis. Jurnal Hukum Ius Quia Iustum Vol 18 No. 1 http://dx.doi.org/10.20885/iustum.vol18.iss1.art4. Diunduh tanggal 23 Juli 2021

Dian Aries Mujiburohman (2018), Potensi Permasalahan Pendaftaran Tanah Sistematik Lengkap (Ptsl) Bhumi, Jurnal Agraria dan Pertanahan Vol. 4 No. 1 Tahun 2018, http://www.stpn.ac.id/jurnalbhumi/JB/article/view/217/204, diunduh 3 Juli 2021

Gawil Despriyatmoko, Rizal Syarief, Agus Maulana,(2016) Tingkat Kepuasan Terhadap Kualitas Pelayanan Pemeliharaan Data Pendaftaran Tanah Di Kantor Pertanahan Kabupaten Bogor, Jurnal Aplikasi Bisnis dan Manajemen, Vol. 2 No.2, Mei 2016. https://journal.ipb.ac.id/index.php/jabm/article/view/12650/9662 diunduh 15 Juli 2021;

Harris Yonatan Parmahan Sibuea (2011), Jurnal Negara Hukum, Volumen 2 No. 2 tahun 2011 http://jurnal.dpr.go.id/index.php/hukum/article/view/218, diunduh 3 Juli 2018

Mustanir, A, \& Lubis, S. (2017). Participatory Rural Appraisal in Deliberations of Development Planning .163(Icodag), 316-319. https://doi.org/10.2991/icodag-17.2017.60 dalam Rozzana Erziaty, et. Al dalam Pemberdayaan Ekonomi Berbasis Syariah Pada Muallaf Dayak Meratus di Dusun Papagaran Mustanir \& Lubis,( 2017), Jurnal Dinamisia, Jurnal Pengabdian Kepada $\begin{array}{llllll}\text { Masyarakat } & \text { Vol. } & 5 & \text { No. } & 3 & \text { Juni }\end{array}$ https://journal.unilak.ac.id/index.php/dinamisia/article/view/4308/3014, diunduh 30 Juli 2021

Rina Yulianti (2021), Penyuluhan Kebijakan Era Normal Baru Sebagai Upaya Pencegahan Penularan Covid-19 Di Kecamatan Kamal, Jurnal Ilmiah Pengabdhi, Volume 7 No 1 April 2021, https://journal.trunojoyo.ac.id/pangabdhi/article/view/9210/5520, diunduh 26 Juli 2021

Rudi Indrajara, et all, (2020) Pengantar, Hukum Agraria, Teori dan Praktik, Refika Aditama, Bandung, 2020,

Pontas.Id, 2020 https://pontas.id/2021/03/05/program-ptsl-jakarta-utara-amburadul-wargajangan-bikin-ribet/, diunduh 25 Juli 2021.

Peraturan Perundang-Undangan

Undang-Undang No. 5 tahun 1960 tentang Peraturan Dasar Pokok-Pokok Agaria

PP No. 24 Tahun 1997 tentang Pendaftaran Tanah

PP No. 18 Tahun 2020 tentang Hak Pengelolaan, Hak Atas Tanah, Rumah Susun serta Pendaftaran Tanah. 